\title{
Differences in Classroom Versus Online Exam Performance Due to Asynchronous Discussion
}

\author{
Robert L. Jorczak \\ Danielle N. Dupuis \\ University of Minnesota
}

\begin{abstract}
This study compares student exam performance of undergraduate students in classroom and online course sections with nearly identical instructional designs. The sections differed only in lecturing and peer discussion activities, which are typical differences of classroom and online instruction. Classroom discussion activities included synchronous speech, while online discussions used asynchronous text. Composite mean exam scores show a large effect size difference that is statistically significant. Results suggest asynchronous peer-to-peer discussion is more effective than traditional classroom lecturediscussion for undergraduate students.
\end{abstract}

\section{INTRODUCTION}

Online instruction, also called web-based instruction, is increasingly used in higher education and K-12 institutions (Allen \& Seaman, 2011). The continuing rapid increase in online instruction raises several important questions. Is this trend beneficial for formal learning? How well do students learn in online instructional environments compared to classrooms? What differences between the environments affect instruction and student learning performance, and why do these differences matter?

The goal of this study was to determine if students performed differently on exams given in nearly identical courses delivered online and in a classroom. Further, if differences existed, this analysis sought to examine potential causes of the differences in student performance. While the courses were delivered via different instructional environments, much of the instructional design of the online and classroom classes was identical.

To understand potential differences between instructional environments that might affect student learning, some concepts must be clearly defined. First, a communication medium is a technological means to store and/or transmit information. Instructional methods are procedures and techniques intended to promote learning of specified outcomes. Instructional methods comprise three functions: presentation of information, specification of learning activities, and assessment. Learning activities go beyond merely presenting information by having students express their knowledge in ways intended to support achievement of learning objectives. Instructional delivery environments, such as classroom and online environments include various media, tools, and functions that support instructional methods.

Using a specific instructional environment does not require the use of specific instructional methods. Online and classroom environments are sufficiently flexible to support a wide range of similar methods. While the two instructional environments can be equivalent in learning effectiveness-since they use similar instructional methods-the environments often differ in preferred methods. Each instructional delivery environment has affordances that guide selection of media and methods. Some methods are easier to implement and/or execute within each environment, and these methods are the ones that tend to be used. Specific designs and design elements are encouraged by aspects of the environment because of 
the efficiency of implementation and use of those designs. Different instructional methods, therefore, tend to be associated with classroom and online environments. This report focuses on what aspects of preferred instructional methods affect learning, as measured by classroom exam performance.

\section{THEORETICAL FRAMEWORK}

Information internalization and externalization by students are important processes for learning (Cress \& Kimmerie, 2008). Internalization occurs when students encounter new information and process that information into knowledge. Students also learn by expressing their knowledge as information. The process of transforming knowledge into external information results in reinforcement of existing knowledge and the creation of new knowledge by increasing associations among internal representations. Information processing models of learning identify elaborative rehearsal as a key control process by which newly-experienced information is merged with existing knowledge in working memory resulting in long-term memory encoding (Raaijmakers \& Shiffrin, 2004). Elaborative rehearsal also plays a role during externalization as knowledge is elaborated during the process of transforming knowledge into externally represented information.

Instructional methods therefore can be productively characterized in terms of presentation of information and specification of learning activities. During information presentation, information is selected and organized to promote internalization of targeted knowledge. Learning activities have students express information in ways thought to promote targeted learning. The concept of "active learning" is the assertion that instructors can most influence learning by designing appropriate learning activities which require deeper processing. Thus, differences in learning activities can be expected to be a key differentiator of learning methods. This perspective suggests that the differences of typical learning activities used in each instructional environment are the major factors distinguishing instructional effectiveness of each environment.

Clark (1994) has asserted that information delivery media, as mere conveyors of information, cannot affect formal learning. Clark suggested that research studies finding an advantage for a particular delivery medium did so because the studies did not compare equivalent instructional methods. Meta-analyses have tended to support this position (Bernard et al., 2004; Means, Toyama, Murphy, Bakia, \& Jones, 2010; Sitzmann, Kraiger, Stewart, \& Wisher, 2006). Means et al. found a statistically significant 0.24 effect size advantage for online and hybrid courses compared to classroom courses. But, the authors issued many cautions about their findings, including the fact that their meta-analysis included many studies that did not use the same instructional methods. These analyses suggest that differences in the effectiveness of instructional environments depend on differences in the instructional methods used in each environment, not on media differences.

The internalization-externalization model can be extended to group learning by viewing social interaction (e.g., discussion) as a means for students to receive divergent information from other students, and also as a means for students to express knowledge relevant to the learning task (Jorczak, 2011). Both learning processes are supported via group discussion that promotes both divergent thinking and elaborative rehearsal. The information internalization-externalization model provides a basis for the social constructivist concept of mutual knowledge construction by social interaction within learning groups.

Table 1

Exam Score Descriptive Statistics by Condition

\begin{tabular}{lllll}
\hline Instructional & & & & \\
Environment & $\mathrm{n}$ & $\mathrm{M}$ & $\mathrm{SD}$ & $\mathrm{SE}(M)$ \\
\hline Classroom & 35 & .67 & .09 & .015 \\
Online & 69 & .74 & .11 & .013
\end{tabular}

Note: Means (M) represent proportion of items answered correct across both exams. SD = standard deviation; $\mathrm{SE}=$ standard error. 


\section{A. Differences in Instructional Methods of Online and Classroom Environments}

The major difference between classroom and online environments is physical presence and synchronicity-classroom environments specify that the instructor and students all be present at the same location and time, while online environments separate instructor and students in location and time. Classroom environments include an information presentation method that is not available to online courses: face-to-face real time speech. Classroom environments are designed to support and promote this presentation method. Online environments cannot, by definition, use this presentation method.

To compare instructional delivery environments and better understand how aspects of those environments affect learning, researchers must look beyond media and consider differences in instructional methods determined or influenced by the nature of the instructional delivery environment. A major difference in instructional method typically found in classroom and online environments involves the synchronicity of the instructional method (the degree to which students experience instruction simultaneously). While both environments can support synchronous and asynchronous learning methods, each displays a preference for one type. Classroom courses tend to use synchronous presentations and activities. Online courses tend to use asynchronous methods (in which students work whenever they choose and instructors interact with students when they choose). Online courses can present information to students synchronously, for example by web-casting a lecture or video to all students at the same time, but this approach is rarely used as it is difficult to implement and does not reflect the flexibility offered by the environment. Classroom courses also can have students do activities (including small group discussion) asynchronously.

\section{B. Interaction and Online Learning}

Classroom and online courses also tend to differ in the type of interaction they promote. A meta-analysis by Bernard et al. (2009) compared interactions in online environments by categorizing interaction into three treatment types: student-content (SC), student-teacher (ST), and student-student (SS). The metaanalysis compared studies that used these types of interaction as well as differences in the "strength" of the interactions. Bernard et al. (2009) found that online ST interactions did not affect learning to the same degree as SC or SS interactions. This result supports the idea that online discussion (which is primarily SS) has a greater effect on learning than teacher-led discussions (which are primarily ST). Classrooms are structured to promote ST interactions, including lecture-discussions. The meta-analysis results suggest a reason for possible differences between student performance in online and classroom environments. The interaction treatment type is an interesting variable, but the categories are broad and ignore important aspects of interaction (e.g., whether it is one-way or two way and the synchronicity of the discussion), so further refinement of the categorization of interaction is required.

\section{Asynchronous Discussion in Support of Learning}

Peer-to-peer guided discussion is an important collaborative learning technique, which has been repeatedly shown to be instructionally effective (Andriessen, Baker \& Suthers, 2003; Garrison, Anderson, \& Archer, 2000). How the method is implemented, which media are used and what instructional methods are used, tend to differ between classroom and online environments. Classroom instructors usually employ synchronous oral lecture-discussion. Online class discussion tends to be done asynchronously via text in "forums" in which students post messages and responses.

Researchers have suggested learning advantages for asynchronous discussion (Garrison et al., 2000; Lapadat, 2002). Asynchronous discussion can be read at whatever pace aids reader understanding, and information can be rescanned and reviewed. Students can take as much time as they wish to respond, so discussion occurs at a much slower pace allowing for more reflection and processing than stream-ofconsciousness speech (Garrison et al., 2000; Lapadat, 2002). No single student has the "floor" to speak, and no time limits are set by either outside constraints or limited attention spans. Knowledge and opinion that is externalized via text requires more effort and cognitive processing than speech. This extra processing improves externalized information and aids organization and specification of knowledge 
(Newman, Webb, \& Cochrane, 1997). Information in asynchronous discussion tends to diverge more (Newman et al., 1997), which aids learning (Jorczak \& Bart, 2009). All students have access to the discussion and all students can contribute as much as they like.

\section{Research Question}

This study adds to the online versus classroom research literature by comparing student performance in online and classroom sections in which most instructional variables were kept constant, with one exception. In this in situ study, the key difference in instructional method is a difference between the discussion learning activities, though some differences in information presentation are also present. The overall goal of this analysis is to seek evidence about whether differences in instructional methods typical of classroom and online courses (i.e., synchronous lecture-discussion versus asynchronous small group discussion) are associated with differences in student exam performance. It is hypothesized that online students using asynchronous discussion will have better exam scores due to the instructional advantages of text-based asynchronous discussion.

\section{METHOD}

\section{A. Participants and Procedures}

Participants were 104 college students (mostly first year students) enrolled in an introductory psychology course at a medium-size Midwestern public university. The course subject was introductory level psychology, and almost all students were required by their program to take the course. Students were enrolled in one of three course sections: a classroom section meeting for one hour three times a week $(n=$ $35)$, and two online sections delivered via a course management system $(n=69)$.

The instructional design for both the classroom and online sections was nearly identical. The classroom and online courses covered identical material following the same sequence as well as the same schedule. The same instructor taught all three sections. Every section used the same materials including the same textbook, recorded videos, as well as supplemental materials (e.g., articles, handouts). Learning activities, such as written assignments, were the same for all three sections with one exception-student discussion.

The instructional method of the online courses differed from the classroom course in information presentation and learning activities. In the classroom section, information was presented to students via lectures by the instructor, prior to in-class discussion. Classroom students also received copies of lecture slides on which they could take notes. Online students, on the other hand, received brief text-based "lectures" covering the same course content.

Learning activities also differed between the two formats. Classroom students participated in both instructor-led and small-group discussion that was synchronous, face-to-face, and via speech; while students in the online sections used asynchronous peer discussion. Online students were graded for discussion participation, while classroom students were not. In short, the classroom course in this study used synchronous lecture-discussion and some synchronous small group discussion, but the online courses used asynchronous small group text discussion as a key instructional activity.

\section{B. Research Design and Data Analysis}

This study is quasi-experimental in design. Students were not randomly assigned to sections. The independent variable is the class delivery environment (online or classroom), and the primary dependent variable is the sum of course exam scores. Students in all sections were given two 50-item exams intended to assess knowledge acquisition and concept formation. These exams were timed and used multiple-choice items that were scored for accuracy (i.e., correct/incorrect). Exams were delivered to all sections via the university's online learning management system. Overall course letter grades were assigned based on the total sum of learning activity points, weekly quiz results, exam scores, research participation points, and discussion participation (online only). Pearson product moment correlations were used to examine the relations between variables; independent-samples t-tests were used to examine 
the mean difference in exam scores between course sections. Effect sizes were calculated following Cohen's $d$.

\section{RESULTS}

Across all exams, the mean proportion correct for classroom students was 0.67 and for the online students 0.74 , which results in a mean difference of 0.08 (see Table 1). The online students did statistically significantly better on the exams, $t(102)=3.56, p=.001$. The effect size was $d=0.66$, which suggests that an average student who participates in online discussion will score 25 percentile points higher on course exams than an average student who participates in classroom discussion. This effect is moderate to large, suggesting that a difference in the classroom and online environments has an important effect on exam performance.

In the online sections, the correlation between exam scores and online discussion participation points was $0.36(p=.002)$, while the correlation between exam scores and all other (non-discussion) learning activities was $0.37(p=.002)$. This result suggests a moderate association between online discussion participation and exam performance, as well as a moderate association between other learning activities and exam performance. For the total sample, the correlation between exam scores and total course points earned in learning activities (excluding online discussion participation points for the online sections) was $0.30(p=.01)$ suggesting that grades do not strictly follow assessed learning. Students with better test scores tended to get better grades, but the association is surprisingly weak. This result suggests that exam results were deemphasized as a determinant of grade in this course design.

Students were not assigned to classes randomly, which damages any causal inferences drawn between the independent (discussion method) and dependent (exam scores) variables. The researchers were not able to access student information outside the course that would allow comparisons of the classroom and online students on variables of interest. An attempt was made to measure group equivalence by comparing group performance on the first course quiz. Quizzes were short multiple-choice tests based on chapter readings. Scores on the first quiz, before the course instructional design had time to take effect, were taken as an indicator of group knowledge and test taking skill prior to any effect of the course. No statistically significant difference was observed between the groups on the first quiz score $(t(105)=0.56, p=.572)$.

\section{DISCUSSION}

A Cohen's $d$ effect size of 0.66 is a moderate to large effect for an instructional intervention (Cohen, 1977). Such a large difference in classroom versus online student performance is not something that is easily ignored or explained away. The observed difference in student exam performance is likely due to differences in the instructional methods. Because the instructional methods used in both sections are so similar, it is reasonable to conclude that the student performance gap stems from differences that did distinguish the classroom and online sections. While the methods differed in both manner of information presentation (lecture versus written information) and learning activities (synchronous oral versus asynchronous text discussion), prior research and theory point to differences in the learning activities as the likely primary cause of performance differences.

Studies comparing oral versus text-based presentation of information have long suggested no difference in effect on student performance (Corey, 1934). In addition, both online and classroom students used the same textbook as an information source. We therefore argue that differences in information presentation between online and classroom sections is negligible for explaining differences in exam performance.

Previous research conducted by Bernard et al., (2009) suggests that student-teacher interactions within classroom lecture-discussions may be partially responsible for the observed lower exam performance of classroom students as compared to the student-student interactions of online students in online discussion. The main difference in learning activities between the sections was synchronous oral teacher-led discussion (classroom) versus asynchronous textural peer discussion (online). We suggest that this 
difference was primarily responsible for the observed difference in exam performance. The cognitive advantages of slowed processing, review ability, and equal access of asynchronous online test discussion appear to provide tangible learning benefits. Students in the online sections may retain information better because they choose when to attend to course information and assignments, as well as when to stop or rest. This learner control can contribute to better learning because students who voluntarily give attention, have the opportunity to direct their attention elsewhere, and return to the point at which there attention wandered, are less likely to miss important information.

This study does not address aspects of effective discussion design but compares the basic functional differences of discussion typically found in online and classroom courses (i.e., synchronous speech versus asynchronous text). Other characteristics of asynchronous discussion design may also affect performance. We stress that the design of discussion in these classes met minimum quality standards that we take to be typical of current online classes and are typical of online courses that use peer discussion.

A potentially important difference in discussion activities is that the online students were graded (i.e., earned points) for their participation in discussion (a common online practice). Classroom students were not assigned participation points and therefore may have had less incentive to participate. This distinction may be responsible for differences in learning due to discussion rather than whether the discussion is synchronous of not. This variable should be controlled in future studies of differences in discussion activities.

If the difference in discussion activity is responsible for the difference in student exam performance, then online courses need to use and refine online asynchronous discussion in support of learning. In addition, classroom courses should move to hybrid designs that incorporate asynchronous discussion activities with the aid of an online forum.

\section{A. Alternative Explanations}

Factors unrelated to differences in instructional methods between the sections could contribute to the observed effect. As mentioned, students were not randomly assigned to classroom and online sections. Therefore, one explanation that cannot be ruled out is that students who choose online courses tend to be more knowledgeable of course subject matter, are better students, have higher learning ability, are more motivated, and/or are better test-takers than their classroom counterparts. Many instructors offer an intuitive opinion that online students tend to be inferior to classroom students. Few studies have addressed this issue, and the ones that have show conflicting results regarding test performance and other variables between classroom and online students (Dutton, Dutton, \& Perry, 2002; Kirtman, 2009) Such studies show that online and classroom students are more similar than different, but that online students report higher levels of interest, curiosity, and intrinsic motivation (Stevens \& Switzer, 2006). Students in the classroom and online sections in this study were found to perform equally on the first quiz, suggesting that students did not differ in their knowledge or ability.

Another possible explanation for the difference in test performance is instructor bias. The suggestion is that the instructor either prefers the online environment or has skills better suited to the online format. This explanation is unconvincing because most aspects of course design are not affected by the instructor during instruction, minimizing the effect of instructor bias in the two courses. The instructor does influence lecture-discussion, and to a lesser degree online discussion, but has minimum effect on all other course activities.

Discrepancies in testing may account for some differences in exam performance. Exams were administered in a very similar way to students in both online and classroom sections. The exams were not "open book", but students in both environments were allowed to create a one-page sheet of notes that they could refer to during the test. Exams were delivered via a learning management system (i.e., by computer) to all students, and were timed to limit opportunities for cheating. For the classroom section, the instructor was present during the administration of both exams which may have discouraged cheating compared to online sections, which were not monitored. 
If discrepancies in testing are responsible for the observed difference in scores, then testing techniques for online exams must be re-evaluated and adjusted. Time limitations on tests should perhaps be decreased to reduce time available to seek answers from sources. The idea of an "open book" test that assesses higher order learning in which simple facts and definitions cannot be simply looked up may be more appropriate for online environments. The use of applications to "lock" browsers from accessing web pages other than the exam may prove useful for online testing (though students can simply use another device to access information). Clearly, more research comparing classroom and online testing is needed along with research about alternative online testing.

\section{B. Limitations}

This study most strictly generalizes to higher education, but there is no reason to expect similar results would not be found for other students if the result is due to differences in discussion activities. The major methodological limitation of this study is the lack of random assignment to groups as discussed above.

The instructor for these courses is also the first author of this report, but the instructor did not know he would conduct this analysis prior to the completion of the course. As a result, no study conditions or any research design strategies were considered or established prior to the completion of the course. The idea to compare test scores came well after the course conclusion of the course. The fact that all classes had the same instructor reduces one potential confounding variable. Nevertheless, this study could be biased if the instructor had a superior ability and/or preference for online instruction. However, it is hard to see how instructor preference could result in such large differences in test scores given that most aspects of the instruction were identical.

This study suggests more experimental work-as well as more theoretical work-is needed regarding asynchronous discussion. In future studies, the effect of discussion synchronicity can be more directly compared by implementing different discussion designs within the same delivery environment. If differences in online instructional methods are identified as being responsible for improved student performance, those methods may be able to be used in classroom or hybrid courses so that these instructional environments can take advantage of their added benefits. 


\section{REFERENCES}

Allen, I. E., \& Seaman, J. (2011). Going the distance: Online education in the United States, 2011. Wellesley, MA: Babson Survey Research Group.

Andriessen, J., Baker, M. J., \& Suthers, D. (2003). Argumentation, computer support, and the educational context of confronting cognitions. In J. Andriessen, J., Baker, M. J., \& Suthers, D. (Eds.), Arguing to learn: Confronting cognitions in computer-supported collaborative learning environments (pp. 1-25). Dordrecht, The Netherlands: Kluwer Academic Publishers.

Bernard, R. M., Abrami, P. C, Borokhovski, E., Wade, C. A., Tamin R. M., Surkes, M. A., \& Bethel, E. C. (2009). A meta-analysis of three types of interaction treatments in distance education. Review of Educational Research, 79, 1243-1289.

Bernard, R. M., Abrami, P. C., Lou, Y., Borokhovski, E., Wade, A., Wozney, L., ... Huang, B. (2004). How does distance education compare with classroom instruction? A meta-analysis of the empirical literature. Review of Educational Research, 74, 379-439.

Clark, R. E. (1994). Media will never influence learning. Educational Technology Research and Development, 42, 21-29.

Cohen, J. (1977). Statistical power analysis for the behavioral sciences. New York, NY: Academic Press.

Corey, S. M. (1934). Learning from lectures vs. learning from readings. Journal of Educational Psychology, 25, 459-470.

Cress, U. \& Kimmerle, J. (2008). A systemtic and cognitive view on collaborative knowledge building with wikis. International Journal of Computer Supported Collaborative Learning, 3, 105-122.

Dutton, J., Dutton, M., \& Perry, J. (2002). How do online students differ from lecture students? Journal of Asynchronous Learning Networks, 6, 1-20.

Garrison, D. R., Anderson, T., \& Archer, W. (2000). Critical inquiry in a text-based environment: Computer conferencing in higher education. The Internet and Higher Education, 2, 1-19. Hammond, M. (2005). A review of recent papers on online discussion in teaching and learning in higher education. Journal of Asynchronous Learning Networks, 9, 9 -23.

Jorczak, R. L. (2011). An information-processing perspective on divergence and convergence in collaborative learning. International Journal of Computer Supported Collaborative Learning, 6, 207-221.

Jorczak, R. L., \& Bart, W. (2009). The effect of task characteristics on conceptual conflict and information processing in online discussion. Computers in Human Behavior, 25, 1165-1171.

Kirtman, L. (2009). Online versus in-class courses: An examination of differences in learning outcomes. Issues in Teacher Education, 18, 103-116.

Lapadat, J. C. (2002). Written interaction: A key component in online learning. Journal of Computer Mediated Communication, 7.

Means, B., Toyama, Y., Murphy, R., Bakia, M., \& Jones, K. (2010). Evaluation of evidence-based practices in online learning: A meta-analysis and review of online learning. Washington, D.C.: U.S. Department of Education, Office of Planning, Evaluation, and Policy Development.

Newman, D. R., Webb, B., \& Cochrane, C. (1997). Evaluating the quality of learning in computersupported cooperative learning. Journal of the American Society for Information Science, 48, 484-495. 
Raaijmakers, J. G. W., \& Shiffrin, R. M. (2004). Models of memory. In H. Pashler \& D. Medin (Eds.) Stevens' Handbook of Experimental Psychology, Third Edition, Volume 2: Memory and Cognitive Processes. New York, NY: Wiley \& Sons, Inc.

Sitzmann, T. K., Kraiger, K, Stewart, D., \& Wisher, R. (2006). The comparative effectiveness of Webbased and classroom instruction: A meta-analysis. Personnel Psychology, 59, 623-664.

Stevens, T., \& Switzer, C. (2006). Online and traditional student differences. Turkish Online Journal of Distance Education, 7, 90-100. 